\title{
Synergistic lipid-lowering effects of Zingiber mioga and Hippophae rhamnoides extracts
}

\author{
SO-HYUN PARK ${ }^{1,2}$, DA-HYE LEE ${ }^{1,2}$, HYUN-IL CHOI $^{2}$, JIYUN AHN $^{1,2}$, YOUNG-JIN JANG ${ }^{2}$, \\ TAE-YOUL HA ${ }^{1,2}$ and CHANG HWA JUNG ${ }^{1,2}$ \\ ${ }^{1}$ Department of Food Biotechnology, University of Science and Technology; ${ }^{2}$ Research Group of Natural Materials \\ and Metabolism, Korea Food Research Institute, Wanju-gun, Jeollabuk-do 55365, Republic of Korea
}

Received March 19, 2019; Accepted December 13, 2019

DOI: $10.3892 /$ etm.2020.8913

\begin{abstract}
The effects of a mixture of Hippophae rhamnoides (HR) and Zingiber mioga (ZM) extract (ZH) on intracellular lipid accumulation were investigated in vitro and the anti-obesity effects of $\mathrm{ZH}$ evaluated in mice with high-fat diet-induced obesity. The results revealed that $\mathrm{ZH}$ inhibited lipid accumulation in 3T3-L1 adipocytes and Huh-7 cells by suppressing adipogenic and lipogenic gene and protein expression. To evaluate the anti-obesity effects of $\mathrm{ZH}$, mice fed a high-fat diet were orally administered low and high doses of $\mathrm{ZH}$ (low, $\mathrm{ZM} 400 \mathrm{mg} / \mathrm{kg}$ + HR $100 \mathrm{mg} / \mathrm{kg}$; high, ZM $800 \mathrm{mg} / \mathrm{kg}$ + HR $200 \mathrm{mg} / \mathrm{kg}$ ) for 9 weeks. ZH significantly reduced body weight gain and adipose tissue accumulation with no reduction in food intake when compared to control treatment. Furthermore, $\mathrm{ZH}$ reduced hepatic triglyceride and total cholesterol levels, as well as adipose cell size, in the liver and epididymal fat pads, respectively, through inhibition of adipogenesis and lipogenesis-related gene expression. These results suggested that $\mathrm{ZH}$ inhibits lipid accumulation, thereby indicating its potential for use as a new therapeutic strategy for obesity.
\end{abstract}

\section{Introduction}

The prevalence of overweight and obesity increasing gradually worldwide, with $\sim 39 \%$ of the population affected (1). Obesity is caused by a chronic energy imbalance due to excessive energy intake and reduced energy expenditure (2). Excessive energy intake due to a high-sugar and high-fat diet (HFD) leads to abnormal lipid accumulation in adipose tissues and in the liver $(3,4)$. The accumulated lipids not only play a role in the development of metabolic syndrome, but also increase the risk of development of diabetes or cardiovascular diseases (5-8).

Correspondence to: Dr Chang Hwa Jung, Research Group of Natural Materials and Metabolism, Korea Food Research Institute, 245 Nongsaengmyeong-ro, Iseo-myeon, Wanju-Gun, Jeollabuk-do 55365, Republic of Korea

E-mail: chjung@kfri.re.kr

Key words: synergistic effect, lipid accumulation, anti-obesity, Zingiber mioga, Hippophae rhamnoides
Many methods have been proposed to overcome this problem, including inducing weight loss through treatment with nutritional supplements with anti-obesity effects (9-12); however, because nutritional supplements are generally less effective than drugs, there is a growing interest in developing combinations of different nutritional supplements that may exhibit synergistic effects, while having low numbers of side effects and increased efficacy (13-15).

Zingiber mioga (of the Zingiberaceae family) is grown in Korea and Japan, where its flower buds are eaten as pickles, in salads and brochettes. It has been suggested to exhibit diverse biological functions, including antihyperglycemic and antioxidant activity, and to improve allergic asthma and memory (16-18). A previous study by our research group demonstrated that Zingiber mioga extract (ZM) exerted an anti-obesity effect in HFD-induced obese mice, and revealed the effects of ZM on insulin resistance and liver gluconeogenesis (19); however, only a high concentration of ZM showed a significant effect in these previous experiments. In order to reach an effective dose, an excessive intake of the extract was required; therefore, combining multiple nutritional supplements could be a useful method for achieving effects at lower concentrations.

Hippophae rhamnoides, also known as sea buckthorn, is grown in cold-temperature climates across Europe and Asia, where its leaves and fruits have been consumed as a traditional medicine to alleviate the symptoms of a variety of diseases, including cough and indigestion $(20,21)$. Several studies report that Hippophae rhamnoides leaf extract (HR) exhibits anti-inflammatory, antioxidative and cytoprotective effects (22-24). Additionally, studies into the effects of $\mathrm{HR}$ in treating obesity report that it inhibits the adipogenic differentiation of 3T3-L1 cells and prevents HFD-induced obesity $(25,26)$. In the present study, a combination of HR and $\mathrm{ZM}(\mathrm{ZH})$ was investigated to establish whether HR and ZM could display synergistic inhibitory effects on adipogenic differentiation and lipid accumulation in 3T3-L1 and Huh-7 cells. Additionally, the anti-obesity effect of $\mathrm{ZH}$ in mice with HFD-induced obesity was explored.

\section{Materials and methods}

Extract preparation. ZM was harvested in September 2017 at Jeongeup-si, Jeollabuk-do (Korea) and lyophilized using 
an LP100 freeze-dryer (IlShin BioBase Co., Ltd.). The dried plants were pulverized and extracted at $80^{\circ} \mathrm{C}$ for $2 \mathrm{~h}$ using a 10 -fold greater volume of water. The extracts were filtered using Advantec filter paper (no. 2; pore size, $5 \mu \mathrm{m}$; Advantec MFS, Inc.), freeze-dried and stored at $-20^{\circ} \mathrm{C}$ until use. HR extract was obtained from Frombio Co., Ltd.

Cell culture. 3T3-L1 and Huh-7 cells were procured from the American Type Culture Collection. 3T3-L1 cells were cultured in DMEM with $10 \%$ calf serum and penicillin/streptomycin/glutamine, and Huh7 cells were cultured in DMEM with $10 \%$ FBS and penicillin-streptomycin (HyClone; GE Healthcare Life Sciences); thereafter, cells were incubated at $37^{\circ} \mathrm{C}$ in a humidified atmosphere with $5 \% \mathrm{CO}_{2}$ for further experiments.

Adipocyte differentiation and lipid accumulation. 3T3-L1 pre-adipocytes were seeded in 6-well plates, and the induction of adipocyte differentiation was initiated after cells reached confluence. Confluent cells were incubated in DMEM containing 10\% FBS, 0.5 mM 3-isobutyl-1-methylxanthine (cat. no. I7018; Sigma-Aldrich; Merck KGaA), $1 \mu \mathrm{M}$ dexamethasone (cat. no. D4902; Sigma-Aldrich; Merck KGaA) and $1 \mu \mathrm{g} / \mathrm{ml}$ insulin (cat. no. I0908; Sigma-Aldrich; Merck KGaA) with different concentration of extracts. The treatment concentrations of ZM and HR were set at $400 \mu \mathrm{g} / \mathrm{ml}$ and $100 \mu \mathrm{g} / \mathrm{ml}$, respectively, based on the results of previous studies $(27,28)$. After 2 days, the medium was replaced with DMEM containing $10 \% \mathrm{FBS}, 1 \mu \mathrm{g} / \mathrm{ml}$ insulin, and cells were incubated for a further 2 days. The medium was again replaced with DMEM containing $10 \%$ FBS and the cells were incubated for a further 2 days, after which the medium was replaced with fresh DMEM containing 10\% FBS every 2 days until day 8 . The extracts were renewed upon each cell medium replacement.

To induce lipid accumulation in Huh7 cells, the cells were seeded into 6 -well plates $\left(2 \times 10^{5}\right.$ cells/well) and treated with $200 \mu \mathrm{M}$ oleic acid (OA; cat. no. O3008; Sigma-Aldrich; Merck $\mathrm{KGaA}$ ) and different concentrations of extracts (ZM, $200 \mu \mathrm{g} / \mathrm{ml}$; HR, $50 \mu \mathrm{g} / \mathrm{ml}$ ) for $24 \mathrm{~h}$. Lipid droplets within Huh7 cells were then quantified following fluorescence detection of Nile Red staining.

Nile Red staining. 3T3-L1 and Huh7 cells were washed with PBS and fixed at room temperature using $4 \%$ formaldehyde for $20 \mathrm{~min}$. The cells were then washed twice with PBS and permeabilized in ice-cold methanol for $20 \mathrm{~min}$ at $-20^{\circ} \mathrm{C}$. The cells were washed again with PBS and then incubated at $37^{\circ} \mathrm{C}$ with PBS-diluted Nile Red stock solution (1:10,000; cat. no. N1142; $10 \mathrm{mg} / \mathrm{ml}$ in acetone; Invitrogen; Thermo Fisher Scientific, Inc.) for $20 \mathrm{~min}$. After further washing with PBS, the cells were stained at room temperature with DAPI (cat. no. 10236276001; Sigma-Aldrich; Merck KGaA; $1 \mu \mathrm{g} / \mathrm{ml}$ ) for 5 min. Images of stained cells were obtained by capturing five different random fields of views for each well using a fluorescence microscope (model IX71; Olympus Corporation), and fluorescence intensities were measured at an excitation wavelength of $488 \mathrm{~nm}$ and an emission wavelength of $550 \mathrm{~nm}$.

Evaluation of synergistic effects. The predicted synergistic effect was calculated using a previously described formula (29): $E=(X \times Y) / 100$; where $X$ is the percentage inhibitory effect of ZM as compared with the control, $\mathrm{Y}$ is the percentage inhibitory effect of HR as compared with the control, and $\mathrm{E}$ is the expected inhibitory percentage of the two-extract mixture $(\mathrm{ZH})$.

BODIPY staining. The OA-treated Huh-7 cells were fixed with $4 \%$ formaldehyde for $15 \mathrm{~min}$ and permeabilized using $0.05 \%$ saponin (cat. no. 47036, Sigma-Aldrich; Merck KGaA) in PBS for $30 \mathrm{~min}$ at room temperature. After blocking with $1 \% \mathrm{BSA}$ for $1 \mathrm{~h}$ at room temperature, the cells were incubated with $1 \mu \mathrm{g} / \mathrm{ml}$ BODIPY 493/503 (cat. no. D2228; Invitrogen; Thermo Fisher Scientific, Inc.) in PBS for $20 \mathrm{~min}$ at $37^{\circ} \mathrm{C}$. Stained cell images were captured using an Eclipse Ti confocal fluorescent microscope (Nikon Corporation).

Reverse transcription-quantitative polymerase chain reaction (RT-qPCR). RNA was extracted using the RNeasy Mini kit (cat. no. 74106; Qiagen $\mathrm{GmbH}$ ) according to the manufacturer's instructions. cDNA was synthesized from $1 \mu \mathrm{g}$ RNA in a volume of $20 \mu \mathrm{l}$ using the ReverTra Ace qPCR RT kit (Toyobo Life Science). qPCR was performed using SYBR-Green real-time PCR master mix (cat. no. FSQ-101; Toyobo Life Science) and the ViiA 7 real-time PCR system (Thermo Fisher Scientific, Inc.). The following thermocycling conditions were applied: Initial denaturation at $95^{\circ} \mathrm{C}$ for $1 \mathrm{~min}$, followed by 40 cycles of $95^{\circ} \mathrm{C}$ for $15 \mathrm{sec}$ and $60^{\circ} \mathrm{C}$ for $1 \mathrm{~min}$. Relative mRNA levels were calculated after normalizing the values against those of $\beta$-actin and the data were analyzed using the $2^{-\Delta \Delta \mathrm{Cq}}$ method (30). The primer sequences used are shown in Table I.

Western blot analysis. Proteins were extracted using radioimmunoprecipitation assay buffer (Thermo Fisher Scientific, Inc.) containing protease inhibitors and phosphatase inhibitors. After centrifugation at $16,000 \mathrm{x} \mathrm{g}$ for $10 \mathrm{~min}$ at $4{ }^{\circ} \mathrm{C}$, the supernatant was removed, and protein concentration was quantified using the Pierce BCA protein assay kit (cat. no. 23227; Thermo Fisher Scientific, Inc.). Proteins (10 $\mu \mathrm{g} /$ lane) were separated by SDS-PAGE (FAS, Vinculin, $\mathrm{C} / \mathrm{EBP} \alpha$ and PPAR $\gamma, 8 \%$; AP2, 12\%) and transferred onto PVDF membranes. After blocking with 5\% skim milk for 1 $\mathrm{h}$ at room temperature, the membranes were incubated with the following primary antibodies diluted $(1: 1,000)$ in TBS-T (0.1\% Tween-20) overnight at $4^{\circ} \mathrm{C}$; Peroxisome proliferator activated receptor $\gamma$ (PPAR $\gamma$; cat. no. sc-7196; Santa Cruz Biotechnology, Inc.); CCAAT/enhancer binding protein- $\alpha$ (C/EBP $\alpha$; cat. no. sc-7962; Santa Cruz Biotechnology, Inc.); sterol regulatory element-binding protein 1 (SREBP1c; cat. no. sc-13551; Santa Cruz Biotechnology, Inc.); $\beta$-actin (cat. no. sc-47778; Santa Cruz Biotechnology, Inc.); adipocyte protein 2 (AP2; cat. no. 2120; Cell Signaling Technology, Inc.); fatty acid synthase (FAS; cat. no. 3180; Cell Signaling Technology, Inc.); and vinculin (cat. no. V9131; Sigma-Aldrich; Merck KGaA). The membranes were incubated with horseradish peroxidase-conjugated secondary antibodies diluted in blocking buffer (1:1,000; cat. nos. NB7539 and NB7160; Novus Biologicals, LLC) at room temperature for $1 \mathrm{~h}$. Immunoreactivity was detected using an enhanced chemiluminescence western substrate (Thermo Fisher Scientific, Inc.) 
Table I. Primer sequences.

\begin{tabular}{lll}
\hline Gene & \multicolumn{1}{c}{ Forward primer $\left(5^{\prime} \rightarrow 3^{\prime}\right)$} & \multicolumn{1}{c}{ Reverse primer $\left(5^{\prime} \rightarrow 3^{\prime}\right)$} \\
\hline AP2 & CCGCAGACGACAGGA & CTCATGCCCTTTCATAAACT \\
PPAR $\gamma$ & TCGCTGATGCACTGCCTATG & GAGAGGTCCACAGAGCTGATT \\
C/EBP $\alpha$ & CAAGAACAGCAACGAGTACCG & GTCACTGGTCAACTCCAGCAC \\
FAS & GGAGGTGGTGATAGCCGGTAT & TGGGTAATCCATAGAGCCCAG \\
CD36 & ATGGGCTGTGATCGGAACTG & GTCTTCCCAATAAGCATGTCTCC \\
SREBP1c & TGGATTGCACATTTGAAGACAT & GCCAGAGAAGCAGAAGAG \\
SCD1 & TTCTTGCGATACACTCTGGTGC & CGGGATTGAATGTTCTTGTCGT \\
$\beta$-actin & GCAGGAGTACGATGAGTCCG & ACGCAGCTCAGTAACAGTCC
\end{tabular}

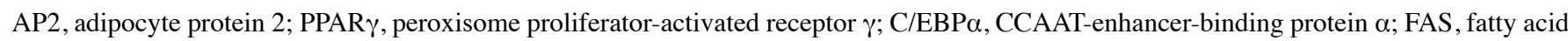
synthase; SREBP1c, sterol regulatory element-binding protein 1; SCD1, acyl-CoA desaturase-1.

and the G:BOX Chemi XX6 imaging system (Syngene) and quantified using ImageJ version 1.8 (National Institutes of Health).

Animal experimental design. Male C57BL/6J mice (age, 4 weeks; weight range, 17.39-19.61 g) were purchased from Orient Bio, Inc. $(\mathrm{n}=40)$. The mice housed under constant conditions (12-h light/dark cycle; temperature, $22 \pm 2^{\circ} \mathrm{C}$; humidity, $50 \pm 10 \%$ ) with ad libitum access to food and water. After 1 week of adaptation, the mice were randomly divided into the following four groups (n=6/group): i) Normal (N); ii) HFD; iii) HFD with a low dose of ZH mixture (ZHL; $\mathrm{ZM} 400 \mathrm{mg} / \mathrm{kg}+\mathrm{HR} 100 \mathrm{mg} / \mathrm{kg}$ ); and iv) HFD with a high dose of ZH mixture (ZHH; ZM $800 \mathrm{mg} / \mathrm{kg}+\mathrm{HR}$ $200 \mathrm{mg} / \mathrm{kg}$ ). The $\mathrm{N}$ group was fed a diet of American Institute of Nutrition (AIN)-76A, including 10\% fat (in kcal), and the other groups were fed a diet of AIN-76A with $45 \%$ fat (in kcal) and $0.5 \%$ cholesterol. The detailed compositions of each diet were described in a previous study (31). Body weight gain was measured weekly for 9 weeks. The design of all animal experiments was approved by the Korea Food Research Institute Animal Care and Use Committee (approval no. KFRI-M-18001). After 9 weeks, the mice were anesthetized with $2 \%$ isoflurane, sacrificed, and the liver and adipose tissues were harvested. The inguinal subcutaneous fat (hereafter referred to as subcutaneous fat) was isolated according to the method of a previous study (32). The liver and epididymal fat pads tissues were fixed in $4 \%$ formaldehyde for $36 \mathrm{~h}$ at $4^{\circ} \mathrm{C}$, whilst the rest were stored at $-80^{\circ} \mathrm{C}$ for further analysis. To obtain serum samples, blood (700-900 $\mu \mathrm{l})$ was collected from the abdominal aorta and centrifuged at $900 \mathrm{x}$ g for $20 \mathrm{~min}$ at $4^{\circ} \mathrm{C}$.

Hematoxylin and eosin $(H \& E)$ staining. The liver and epididymal fat pads (EPs) were fixed in $4 \%$ formaldehyde for $36 \mathrm{~h}$, embedded in paraffin, cut into $5-\mu \mathrm{m}$ sections. The sections were deparaffinized using xylene and were stained with H\&E (hematoxylin; $5 \mathrm{~min}$, eosin; $1 \mathrm{~min}$ ) at room temperature. The samples were then observed under a microscope (magnification, x100; model IX71; Olympus Corporation), and adipose-tissue sizes were measured using iSolution DT 9.2 software (IMT i-Solution, Inc.)
Hepatic triglyceride (TG) and total cholesterol (TC) levels. Hepatic lipids were extracted using a method described by Folch et al (33). Lipid composition was measured using TG (cat. no. M-209-1), TC (cat. no. M-206-1) and high-density lipoprotein (cat. no. M-208-1) quantification kits (EMBIEL Ltd.).

Statistical analysis. Significant differences among groups were evaluated by one-way ANOVA, followed by Tukey's post hoc multiple comparison test using GraphPad Prism version 7 (GraphPad Software, Inc.). Data are presented as the mean $\pm \mathrm{SD}$ (in vitro) or SEM (in vivo). $\mathrm{P}<0.05$ was considered statistically significant.

\section{Results}

Synergistic inhibitory effect of ZM and HR on the differentiation of 3T3-L1 preadipocytes. To investigate the potential synergistic inhibitory effects of HR and ZM on obesity, the inhibitory effects of ZH on 3T3-L1 cell differentiation were examined and the effects was measured using Nile Red staining. ZM or HR treatment suppressed the adipogenic differentiation of 3T3-L1 cells by $\sim 15$ and $\sim 60 \%$, respectively, relative to untreated controls. Based on the formula proposed by Colby (29), the expected inhibition by the ZH mixture was calculated at $66 \%$, indicating that $\mathrm{ZH}$ treatment was more effective than predicted, as lipid accumulation was shown to be inhibited by $\sim 70 \%$ (Fig. 1A and B). Additionally, levels of FAS, C/EBP $\alpha$, PPAR $\gamma$ and AP2, which are key markers of the differentiation process, were analyzed, and the results suggested that the mRNA and protein levels of these adipogenesis-related genes in 3T3-L1 adipocytes were significantly reduced in $\mathrm{ZH}$-treated cells relative to cells treated with a single extract (Fig. 1C and D). These results indicated that ZM and HR exerted a synergistic effect on adipocyte differentiation by suppressing the expression of adipogenesis-related genes more effectively than single extracts.

Synergistic inhibitory effects of ZM and HR on OA-induced lipid accumulation in hepatocytes. Whether ZM and HR would also show a synergistic inhibitory effect on lipid accumulation was then investigated in hepatocytes. Although HepG2 is the most common in vitro model used in fatty liver studies, Huh-7 
A
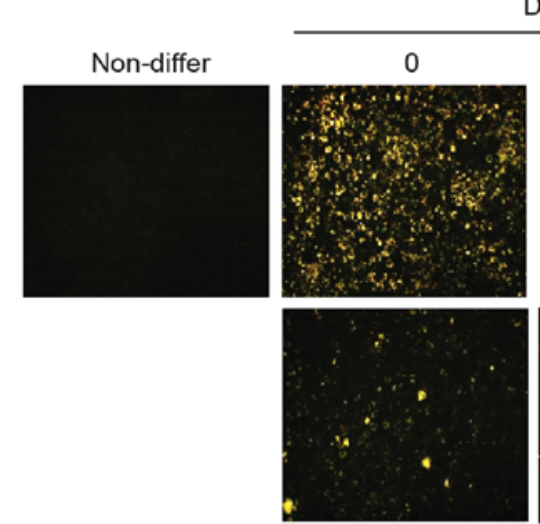

$\mathrm{ZM}+\mathrm{HR}$
Diff
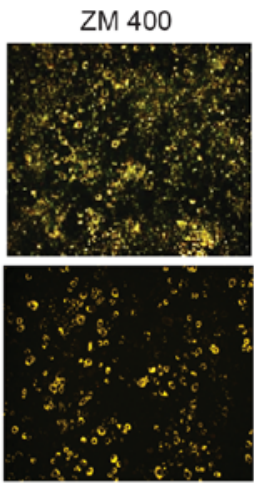

HR 100

Diff

C

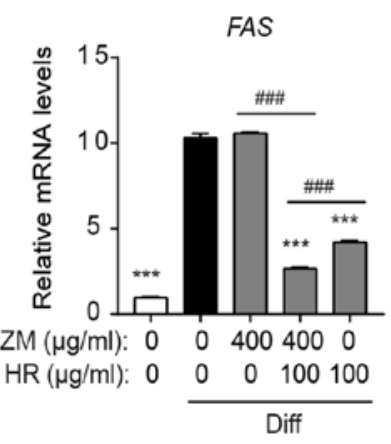

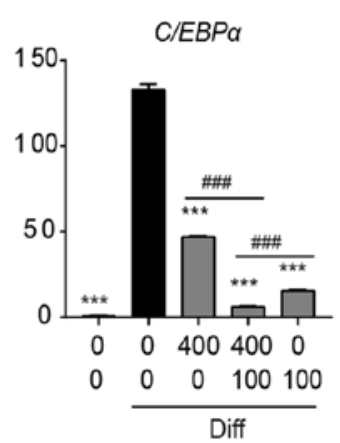

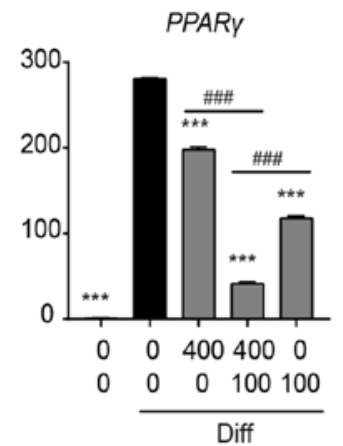

B

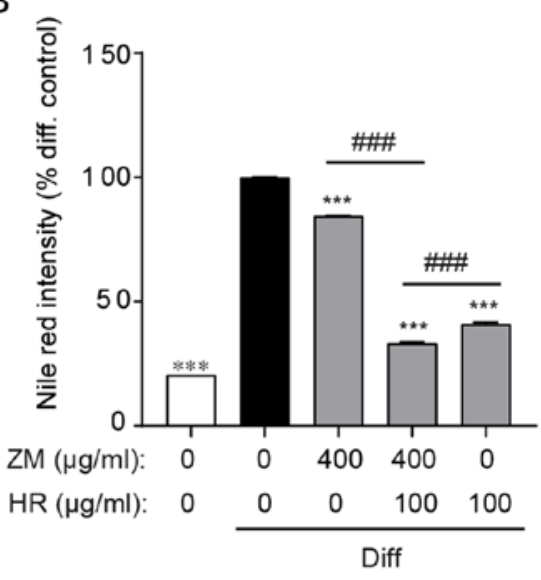

D
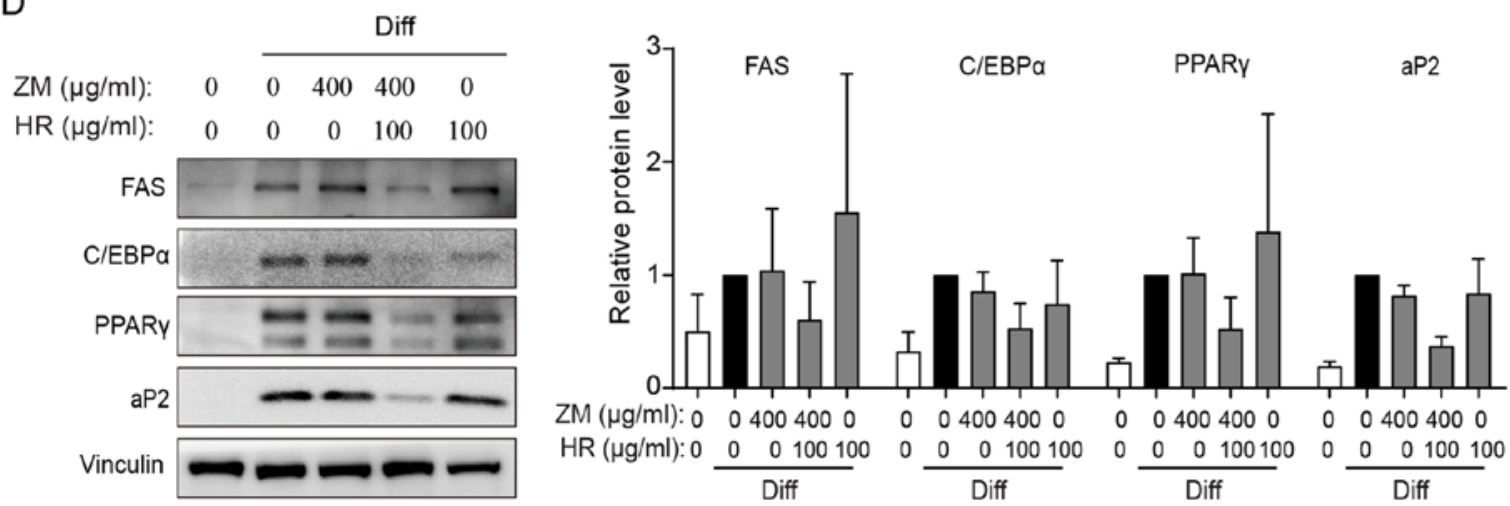

Figure 1. Effects of ZH on 3T3-L1 cell adipogenic differentiation. (A) Lipid droplets stained with Nile Red dye and (B) their fluorescence intensity (original magnification, x100). (C) Relative mRNA levels of $F A S, C / E B P \alpha, P P A R \gamma$ and $A P 2$ and (D) protein levels and fold changes normalized to those in the differentiation control group. Data represent the mean $\pm \mathrm{SD}$ of triplicate experiments. ${ }^{* * *} \mathrm{P}<0.001$ vs. differentiation control group; ${ }^{\# \#} \mathrm{P}<0.001$. diff, differentiation; AP2, adipocyte protein 2; C/EBP $\alpha$, CCAAT-enhancer-binding protein $\alpha$; FAS, fatty acid synthase; HR, Hippophae rhamnoides; PPAR $\gamma$, peroxisome proliferator-activated receptor $\gamma ; \mathrm{ZM}$, Zingiber mioga; ZH, ZM and HR extract mixture.

cells can also be used to model lipid accumulation in hepatocytes $(34,35)$. To examine the effects, OA treated Huh-7 cell with or without extract treatment were analyzed for changes in lipid accumulation using Nile Red staining. ZM or HR treatment alone reduced lipid accumulation in Huh7 cells by $\sim 50$ and $\sim 45 \%$, respectively, as compared with untreated controls. The predicted value based on the Colby equation $(61 \%)$ indicated that the lipid-lowering effect in the ZH-treated cells $(\sim 65 \%)$ was $4 \%$ higher than that predicted (Fig. $2 \mathrm{~A}$ and $\mathrm{B}$ ). To confirm the synergistic effects of ZM and HR, lipid accumulation was analyzed using BODIPY staining and the results suggested that $\mathrm{ZH}$ reduced lipid accumulation more effectively than either single extract (Fig. 2C). Additionally, ZM and HR treatment showed a synergistic inhibitory effect on protein levels of FAS, a factor involved in lipid synthesis (Fig. 2D). These results suggested that $\mathrm{ZH}$ exerted a greater inhibitory effect on lipid accumulation in hepatocytes than either ZM or HR alone.

Effect of $\mathrm{ZH}$ on body weight gain and organ weight in $H F D$-induced obese mice. It was next determined whether $\mathrm{ZH}$ would show anti-obesity effects in an animal model. The ZHL and $\mathrm{ZHH}$ groups showed significantly reduced gains in body weight as compared with the HFD group, with no differences in food intake during the HFD feeding period (Fig. 3A, B and D). To investigate whether this difference was due to the inhibition of lipid accumulation, the weights of the liver and adipose 

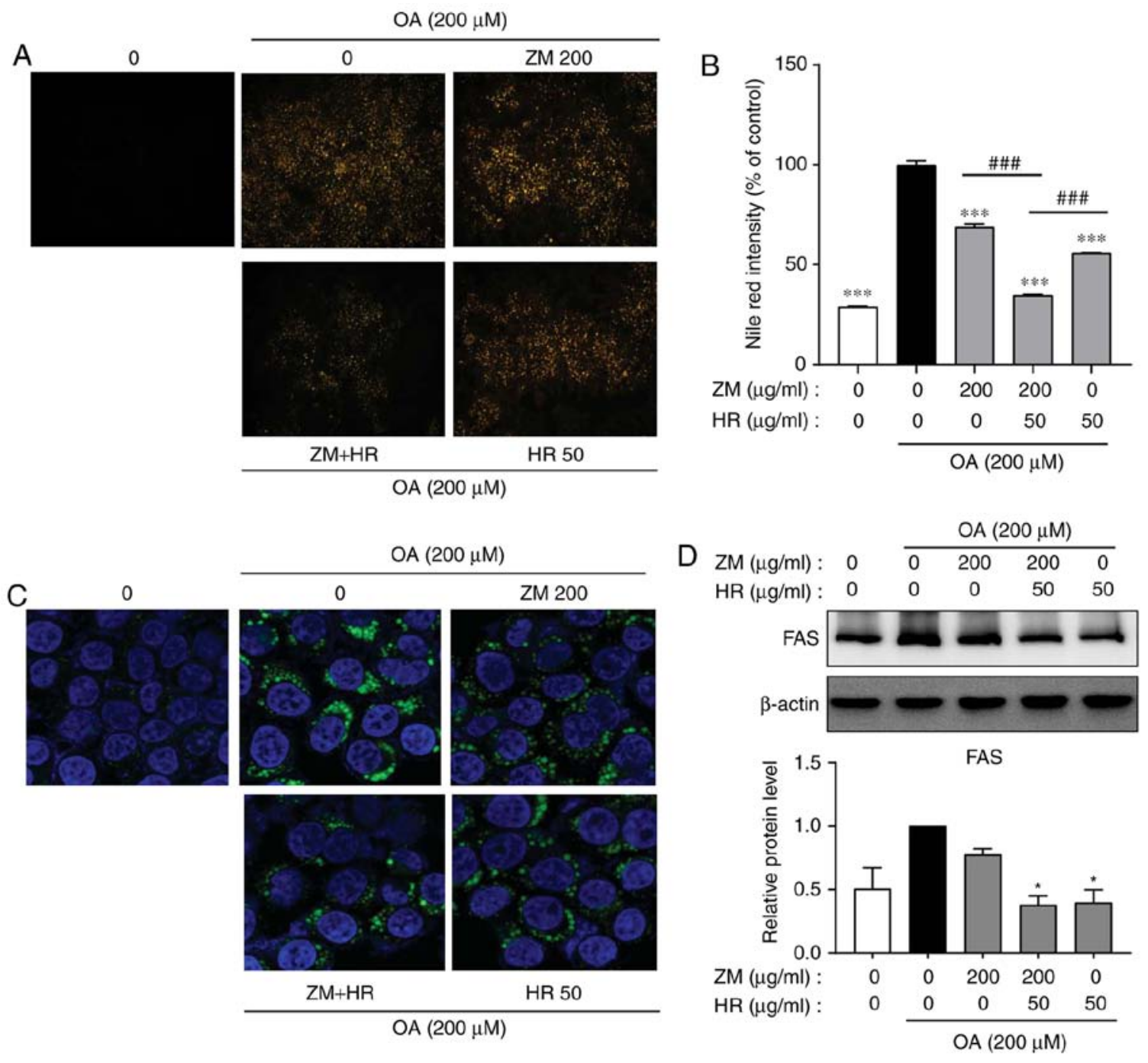

Figure 2. Effects of ZH on OA-induced lipid accumulation in Huh-7 cells. (A) Lipid droplets stained with Nile Red and (B) their fluorescence intensity (original magnification, x100). (C) Lipid droplets evaluated by BODIPY staining (original magnification, x600). (D) Protein levels of FAS and the fold change normalized to that in the OA-treated control group. Data represent the mean \pm SD of triplicate experiments. FAS, fatty acid synthase; HR, Hippophae rhamnoides; $\mathrm{OA}$, oleic acid; ZM, Zingiber mioga. ${ }^{*} \mathrm{P}<0.05,{ }^{* * * *} \mathrm{P}<0.001$ vs. OA-treated control; ${ }^{\# \#} \mathrm{P}<0.001$. FAS, fatty acid synthase; HR, Hippophae rhamnoides; OA, oleic acid; ZM, Zingiber mioga; ZH, ZM and HR extract mixture.

tissues from mice in all groups were measured. Both ZHL and ZHH reduced liver weight significantly, and the subcutaneous fat weight was significantly reduced in only the ZHH group (Fig. 3C). Although the weight of epididymal fat tissues was reduced in ZHH group compared with HFD group, no significant differences were observed (Fig. 3C). H\&E staining of the liver showed that both the ZHL and ZHH groups displayed reduced lipid accumulation as compared with the HFD group (Fig. 3E). Additionally, analysis of TG and TC concentrations indicated that the $\mathrm{ZH}$ groups showed reductions in both TG and TC concentrations as compared with those in the HFD group (Fig. 3G). Additionally, adipocytes in the EPs were smaller in mice in the $\mathrm{ZH}$ groups than in those from the HFD group (Fig. 3F and $\mathrm{H}$ ), although $\mathrm{ZH}$ supplementation did not significantly reduce EP weight. These results suggested that $\mathrm{ZH}$ supplementation effectively reduced the size of adipocytes in white adipose tissue and lipid accumulation in the liver.

Effect of ZH on mRNA expression of liver lipogenic and WAT adipogenic genes. Whether $\mathrm{ZH}$ reduces the mRNA expression of lipogenic and adipogenic genes in the liver and EPs was next examined. SREBPIC, SCDI and FAS in the liver and $P P A R \gamma, A P 2$ and $C / E B P \alpha$ in adipose tissue are associated with lipogenesis and adipogenesis, respectively $(36,37)$. In the liver, SREBPIC and SCDI levels decreased significantly in the $\mathrm{ZHH}$ group as compared with those in the HFD group, whereas FAS expression decreased slightly but not significantly (Fig. 4A). All other genes showed no significant difference in expression in the ZHL group as compared with the HFD group, although their expression levels were slightly reduced. Additionally, PPAR $\gamma$ expression was only significantly reduced by $\mathrm{ZHH}$ supplementation in EPs (Fig. 4B). These results suggested that ZHH administration to HFD-induced obese mice partially suppressed the expression of adipogenic genes in the liver and EPs.

\section{Discussion}

Studies are currently underway to demonstrate the synergistic effects of two or more substances to improve the physiological 

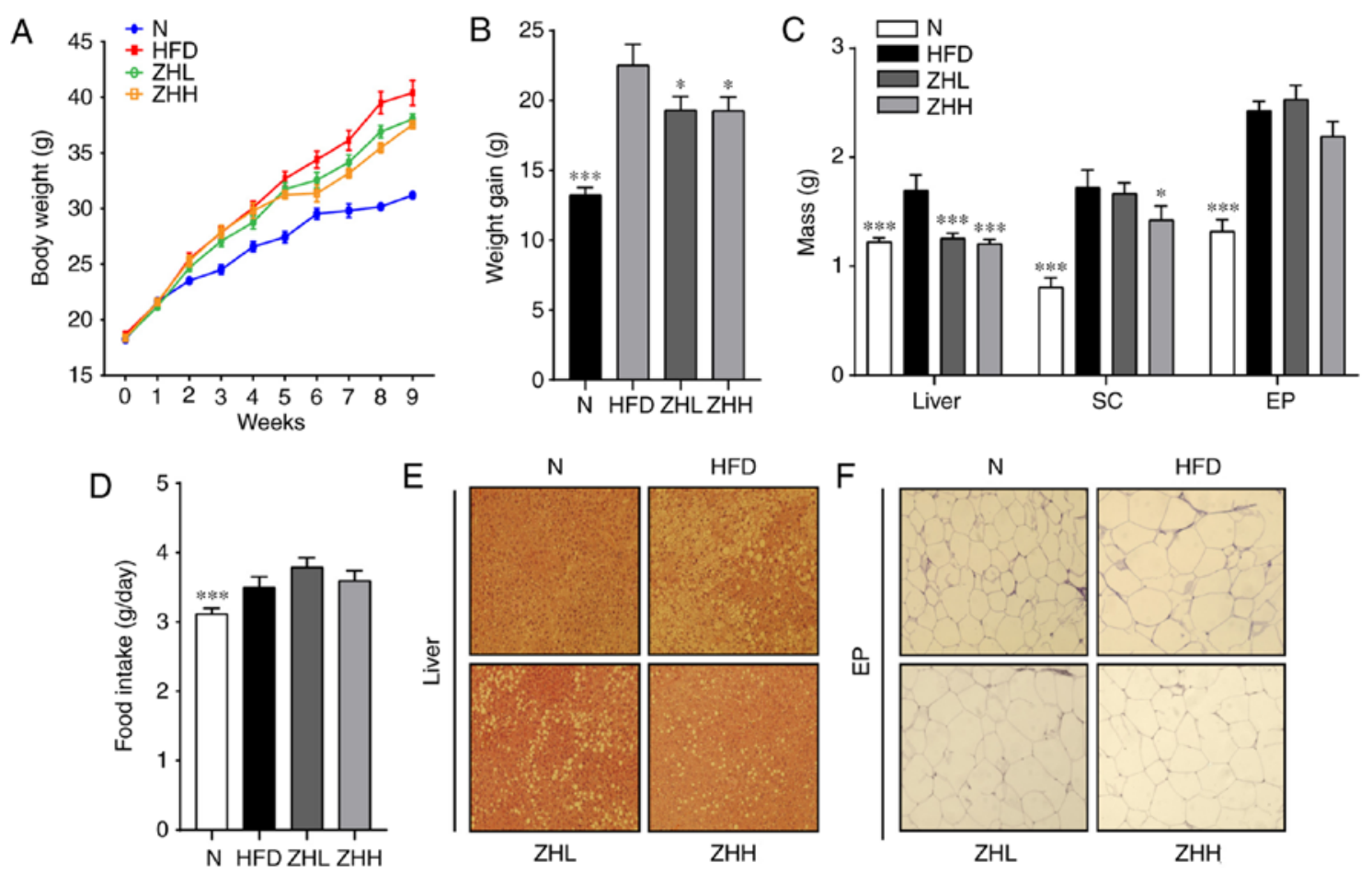

HFD
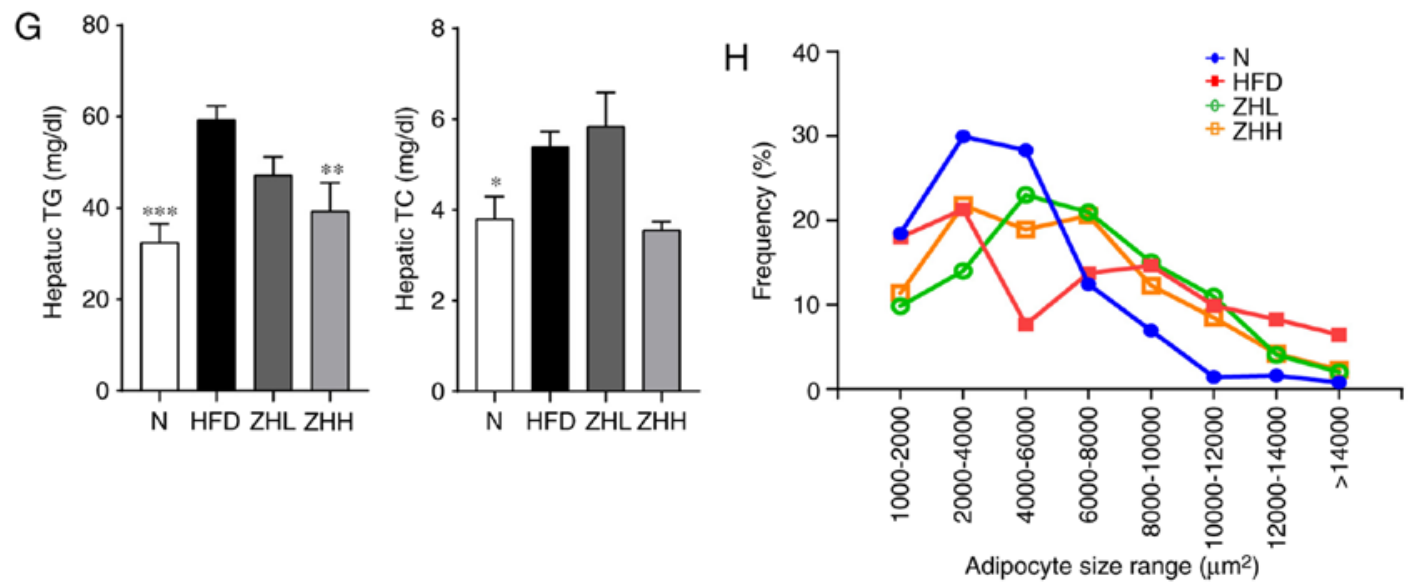

Figure 3. Anti-obesity effects of ZH in HFD-fed mice. (A) Body weight change and (B) body weight gain during 9 weeks of ZH supplementation in HFD-fed mice. (C) Liver and adipose tissue weights. (D) Food intake. (E) Hematoxylin and eosin staining of the liver and (F) EPs (original magnification x200). (G) Hepatic TG and TC levels in each group. (H) Frequency of adipocyte cell size in EPs. Data represent the mean $\pm \mathrm{SEM}$. $\mathrm{n}=6 \mathrm{mice} / \mathrm{group} .{ }^{*} \mathrm{P}<0.05{ }^{* * *} \mathrm{P}<0.01$, and ${ }^{* * *} \mathrm{P}<0.001$ vs. HFD group. EP, epidymal fat pad; H, high-dose; HFD, high fat diet; HR, Hippophae rhamnoides; L, low-dose; N; Normal fat diet; TC, total cholesterol; TG, triglyceride; ZM, Zingiber mioga; ZH, ZM and HR extract mixture.

activity of well-known materials, with the aim of developing nutritional supplements or dietary supplements $(15,38,39)$. Until recently, most studies have focused on identifying the efficacy of single materials rather than mixtures. Studies of the synergistic effects of a mixture comprised of two or more materials to promote human health could provide more favorable alternative treatment options. In the present study, the inhibitory effects of the $\mathrm{ZH}$ mixture on lipid accumulation in vitro were examined and its anti-obesity effects in HFD-induced obese mice evaluated. The results indicated that treatment with individual extracts inhibited lipid accumulation in 3T3-L1 adipocytes, as shown in previous studies $(19,25)$. This effect was found to be higher than predicted (using the equation proposed by Colby (29) following treatment with a mixture containing both materials. Subsequent evaluation of the efficiency of the mixture in reducing lipid accumulation revealed that ZM and HR displayed a synergistic effect in reducing lipid accumulation in 3T3-L1 adipocytes and hepatocytes.

Various intracellular proteins participate in adipocyte differentiation in 3T3-Ll cells. Specifically, PPAR and C/EBP $\alpha$ are transcription factors that induce the expression of several genes involved in adipogenic differentiation (40). Previous studies have shown that ZM and HR inhibit fat accumulation by suppressing the expression of these genes $(19,26)$. The results of the present study indicated that $\mathrm{ZH}$ treatment inhibited the expression of genes related to adipocyte differentiation in 3T3-L1 cells to a degree greater than that observed following treatment with either single extract. Moreover, $\mathrm{ZH}$ suppressed lipid accumulation more effectively than the single extracts in hepatocytes exhibiting OA-induced lipid accumulation. However, this study did not identify a mechanism controlling 

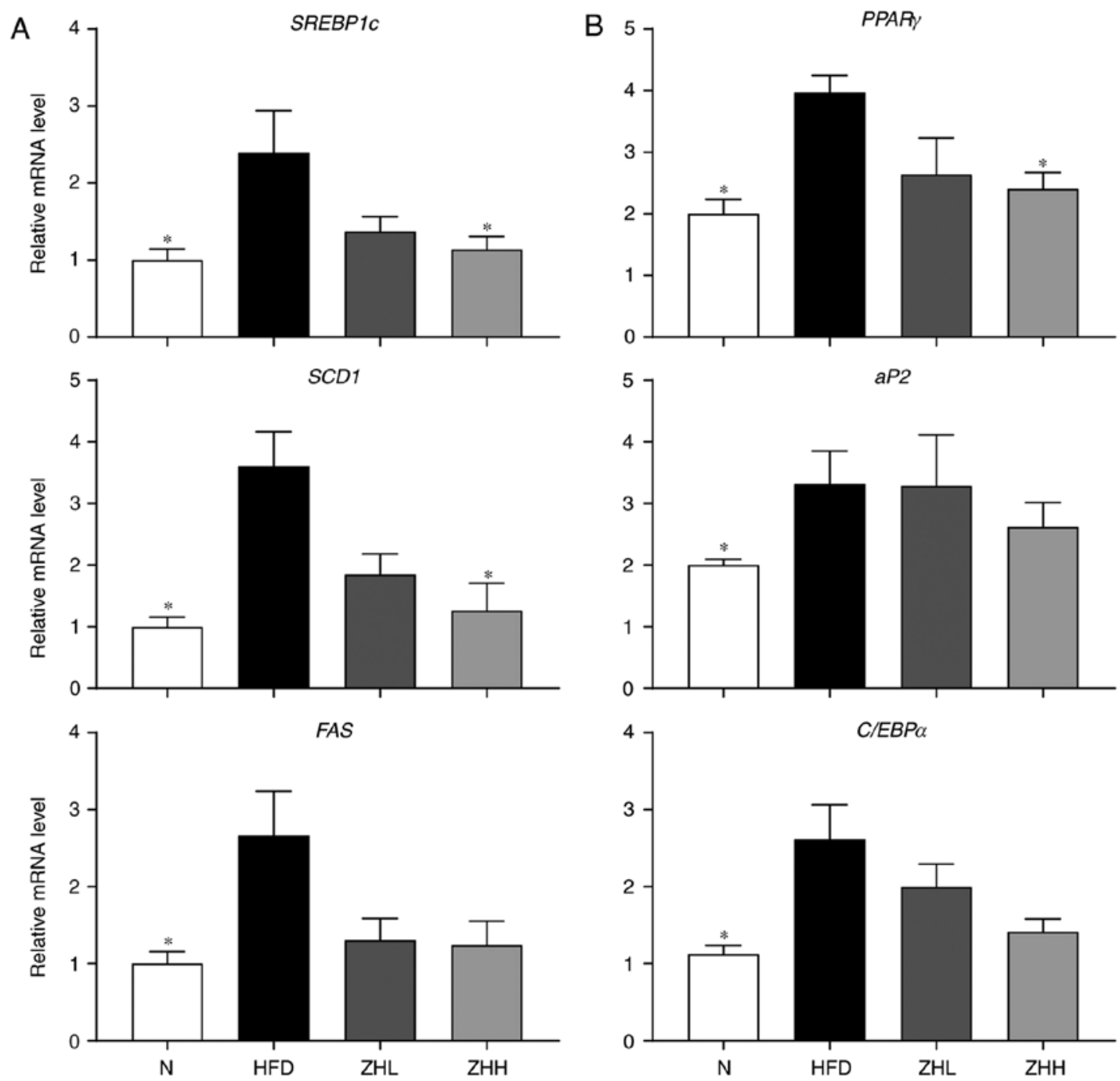

Figure 4. Effects of ZH on lipogenesis- and adipogenesis-related mRNA levels. (A) mRNA levels of SREBPIc, SCD1 and FAS in the liver (n=6). (B) mRNA levels of $P P A R \gamma, A P 2$ and $C / E B P \alpha$ in EPs $(\mathrm{n}=6)$. Data represent the mean \pm SEM. ${ }^{*} \mathrm{P}<0.05$ vs. HFD group. AP2, adipocyte protein 2 ; C/EBP $\alpha, C C A A T-$ enhancer-binding protein $\alpha$; FAS, fatty acid synthase; HR, Hippophae rhamnoides; PPAR $\gamma$, peroxisome proliferator-activated receptor $\gamma$; SCD1, acyl-CoA desaturase-1; SREBP1c, sterol regulatory element-binding protein 1; ZM, Zingiber mioga; ZH, ZM and HR extract mixture.

the lipid-lowering effect of ZH. To elucidate such a mechanism, it will be necessary to identify the functional components in each extract, followed by confirmation of additional effects between the components. ZM is a perennial herb whose flower buds have a pungent aroma and flavor caused, at least in part, by the presence of mioganal and miogadial $(41,42)$. A previous study reported that miogadial stimulates the transient receptor potential (TRP) cation channel V1 and TRPA1 receptors (43); however, to the best of our knowledge, there have been no studies focused on their roles in relation to obesity. The leaves of HR are reportedly rich in flavonols, such as kaempferol, isorhamnetin and quercetin glycosides (44), with many studies demonstrating that these flavonol glycosides exert an inhibitory effect on lipid accumulation $(45,46)$. Furthermore, recent studies have been conducted to improve their specific functions by mixing different compounds $(47,48)$. Further research is required to determine which components of HR and ZM display the synergistic effects observed here.

To investigate whether $\mathrm{ZH}$ reduces lipid accumulation in vivo, its anti-obesity effect in HFD-induced obese mice was investigated. ZH treatment significantly reduced body weight gain in obese mice as compared to that in the control group; however, no concentration-dependent effects were observed, and its activity was effective even at a lower concentration. Obesity is characterized by an increase in the size of adipocytes (49), a major component of adipose tissue. Here, the results suggested that $\mathrm{ZH}$ treatment significantly decreased adipocyte size. Obesity can be prevented by decreasing adipogenesis and inhibiting lipogenesis (50). Adipocyte formation is regulated by a cascade of transcription factors, including PPAR $\gamma$ and C/EBP, which are master regulators of adipocyte differentiation and regulate the expression of downstream target genes, such as $A P 2, F A S$ and $S C D 1$, leading to lipid accumulation in cells $(40,51)$. In the present study, ZH treatment resulted in a slight decrease in $C / E B P \alpha$ and $A P 2$ levels, with only $P P A R \gamma$ expression showing a significant decline. Increasing the number of experimental animals will potentially provide more meaningful results.

The effects of $\mathrm{ZH}$ treatment were more prominent in the liver, as shown by the significant reduction in liver weight and lipid accumulation in the present study. SREBP1c is a transcription factor that induces the expression of lipogenesis-related 
genes, such as FAS and SCD1 (52). An HFD stimulates fat production through activation of these genes in the liver and causes hepatic steatosis (53-55). $\mathrm{ZH}$ effectively reduced the mRNA levels of SREBPIc, FAS and SCD1, which might have triggered a reduction in lipid and TG accumulation in the liver. In particular, these mRNA levels were significantly reduced in the $\mathrm{ZHH}$ group as compared with the HFD group.

The results of the present study suggested that $\mathrm{ZH}$ inhibited adipocyte differentiation and hepatic lipid accumulation, and that this effect was significantly more pronounced than that of treatment with each extract alone. Furthermore, the results suggested that the $\mathrm{ZH}$ mixture suppressed lipid accumulation in the liver and adipose tissue by regulating gene expression in vivo.

\section{Acknowledgements}

Not applicable.

\section{Funding}

This study was supported by the Korea National Food Cluster and Korea Food Research Institute (grant no. E0133109-05).

\section{Availability of data and materials}

The datasets used and/or analyzed during the current study are available from the corresponding author on reasonable request.

\section{Authors' contribution}

CHJ contributed to the study concept and design; $\mathrm{CHJ}$ and SHP wrote the manuscript; SHP, HIC and DHL performed the in vivo experiments; SHP and DHL performed the in vitro experiments; and JA supported in vivo experiment design and related result analyses. YJJ and TYH contributed in the revisions of manuscript and performed statistical analysis. All authors read and approved the final manuscript.

\section{Ethics approval and consent to participate}

This study was approved by the Korea Food Research Institute Ethnics Committee (approval no. KFRI-M-18001).

\section{Patient consent for publication}

Not applicable.

\section{Competing interests}

The authors declare that they have no competing interests.

\section{References}

1. Chooi YC, Ding C and Magkos F: The epidemiology of obesity. Metabolism 92: 6-10, 2019.

2. Spiegelman BM and Flier JS: Obesity and the regulation of energy balance. Cell 104: 531-543, 2001.

3. Ishimoto T, Lanaspa MA, Rivard CJ, Roncal-Jimenez CA, Orlicky DJ, Cicerchi C, McMahan RH, Abdelmalek MF, Rosen HR, Jackman MR, et al: High-fat and high-sucrose (western) diet induces steatohepatitis that is dependent on fructokinase. Hepatology 58: 1632-1643, 2013.
4. Tang LL, Tang XH, Li X, Yu HB, Xie ZG, Liu XY and Zhou ZG: Effect of high-fat or high-glucose diet on obesity and visceral adipose tissue in mice. Zhongguo Yi Xue Ke Xue Yuan Xue Bao 36: 614-619, 2014

5. Nishimura S, Manabe I and Nagai R: Adipose tissue inflammation in obesity and metabolic syndrome. Discov Med 8: 55-60, 2009.

6. Bergman RN and Ader M: Free fatty acids and pathogenesis of type 2 diabetes mellitus. Trends Endocrinol Metab 11: 351-356, 2000.

7. Wilson PW, D'Agostino RB, Sullivan L, Parise H and Kannel WB: Overweight and obesity as determinants of cardiovascular risk: The Framingham experience. Arch Intern Med 162: 1867-1872, 2002.

8. Landsberg L, Aronne LJ, Beilin LJ, Burke V, Igel LI,Lloyd-Jones D and Sowers J: Obesity-related hypertension: Pathogenesis, cardiovascular risk, and treatmen - a position paper of the The Obesity Society and The American Society of Hypertension. Obesity (Silver Spring) 21: 8-24, 2013.

9. Hiraki E, Furuta S, Kuwahara R, Takemoto N, Nagata T, Akasaka T, Shirouchi B, Sato M, Ohnuki K and Shimizu K: Anti-obesity activity of Yamabushitake (Hericium erinaceus) powder in ovariectomized mice, and its potentially active compounds. J Nat Med 71: 482-491, 2017.

10. Abdul Kadir NA, Rahmat A and Jaafar HZ: Protective effects of tamarillo (Cyphomandra betacea) extract against high gat fiet induced obesity in Sprague-Dawley rats. J Obes 2015: 846041, 2015.

11. Kim SJ, Bang CY, Guo YR and Choung SY: Anti-obesity effects of Aster spathulifolius extract in high-fat diet-induced obese rats. J Med Food 19: 353-364, 2016.

12. Zhang T, Yamashita Y, Yasuda M, Yamamoto N and Ashida H: Ashitaba (Angelica keiskei) extract prevents adiposity in high-fat diet-fed C57BL/6 mice. Food Funct 6: 135-145, 2015.

13. Lim Y, Song TJ, Hwang W, Kim JY, Lee D, Kim YJ and Kwon O: Synergistic effects of Sanghuang-Danshen bioactives on arterial stiffness in a randomized clinical trial of healthy smokers: An integrative approach to in silico Network analysis. Nutrients 11: $108,2019$.

14. Pan H, Li J, Rankin GO, Rojanasakul Y, Tu Y and Chen YC: Synergistic effect of black tea polyphenol, theaflavin-3,3'-digallate with cisplatin against cisplatin resistant human ovarian cancer cells. J Funct Foods 46: 1-11, 2018.

15. Fang XS, Hao JF, Zhou HY, Zhu LX, Wang JH and Song FQ: Pharmacological studies on the sedative-hypnotic effect of Semen Ziziphi spinosae (Suanzaoren) and Radix et Rhizoma Salviae miltiorrhizae (Danshen) extracts and the synergistic effect of their combinations. Phytomedicine 17: 75-80, 2010.

16. Cho C: Anti-hyperglycemic and antioxidant activities of Zingiber mioga extracts. Journal, 2014.

17. Shin NR, Shin IS, Jeon CM, Hong JM, Kwon OK, Kim HS, Oh SR, Hahn KW and Ahn KS: Zingiber mioga (Thunb.) Roscoe attenuates allergic asthma induced by ovalbumin challenge. Mol Med Rep 12: 4538-4545, 2015.

18. Kim HG, Lim S, Hong J, Kim AJ and Oh MS: Effects of myoga on memory and synaptic plasticity by regulating nerve growth factor-mediated signaling. Phytother Res 30: 208-213, 2016.

19. Lee DH, Ahn J, Jang YJ, Ha TY and Jung CH: Zingiber mioga reduces weight gain, insulin resistance and hepatic gluconeogenesis in diet-induced obese mice. Exp Ther Med 12: 369-376, 2016.

20. Suryakumar G and Gupta A: Medicinal and therapeutic potential of sea buckthorn (Hippophae rhamnoides L.). J Ethnopharmacol 138: 268-278, 2011.

21. Guliyev VB, Gul M and Yildirim A: Hippophae rhamnoides $\mathrm{L}$ : Chromatographic methods to determine chemical composition, use in traditional medicine and pharmacological effects. J Chromatogr B Analyt Technol Biomed Life Sci 812: 291-307, 2004

22. Ganju L, Padwad Y, Singh R, Karan D, Chanda S, Chopra MK, Bhatnagar P, Kashyap R and Sawhney RC: Anti-inflammatory activity of Seabuckthorn (Hippophae rhamnoides) leaves. Int Immunopharmacol 5: 1675-1684, 2005.

23. Cho CH, Jang H, Lee M, Kang H, Heo HJ and Kim DO: Sea buckthorn (Hippophae rhamnoides L.) leaf extracts protect neuronal PC-12 cells from oxidative stress. J Microbiol Biotechnol 27: 1257-1265, 2017.

24. Upadhyay NK, Kumar MS and Gupta A: Antioxidant, cytoprotective and antibacterial effects of Sea buckthorn (Hippophae rhamnoides L.) leaves. Food Chem Toxicol 48: 3443-3448, 2010 . 
25. Yang ZG, Wen XF, Li YH, Matsuzaki K and Kitanaka S: Inhibitory effects of the constituents of Hippophae rhamnoides on 3T3-L1 cell differentiation and nitric oxide production in RAW264.7 cells. Chem Pharm Bull (Tokyo) 61: 279-285, 2013.

26. Pichiah PB, Moon HJ, Park JE, Moon YJ and Cha YS: Ethanolic extract of seabuckthorn (Hippophae rhamnoides L.) prevents high-fat diet-induced obesity in mice through down-regulation of adipogenic and lipogenic gene expression. Nutr Res 32: 856-864, 2012.

27. Jeong HJ, Park JH and Kim MJ: Ethanol extract of Hippophae rhamnoides L. leaves inhibits adipogenesis through AMP-activated protein kinase (AMPK) activation in 3T3-L1 preadipocytes. Korean J Plant Resour 28: 582-590, 2015.

28. Iwashita K, Yamaki K and Tsushida T: Mioga (Zingiber mioga Rosc.) extract prevents 3T3-L1 differentiation into adipocytes and obesity in mice. Food Sci Technol Res 7: 164-170, 2001.

29. Colby S: Calculating synergistic and antagonistic responses of herbicide combinations. Weeds 15: 20-22, 1967.

30. Livak KJ and Schmittgen TD: Analysis of relative gene expression data using real-time quantitative PCR and the $2^{-\Delta \Delta C}$ method. Methods 25: 402-408, 2001.

31. Park SH, Lee DH, Kim MJ, Ahn J, Jang YJ, Ha TY and Jung CH: Inula Japonica Thunb. Flower ethanol extract improves obesity and exercise endurance in mice fed a high-fat diet. Nutrients 11: 11,2018

32. Mann A, Thompson A, Robbins $\mathrm{N}$ and Blomkalns AL: Localization, identification, and excision of murine adipose depots J Vis Exp: Dec 4, 2014 (Epub ahead of print), doi: 10.3791/52174.

33. Folch J, Lees M and Sloane Stanley GH: A simple method for the isolation and purification of total lipides from animal tissues. J Biol Chem 226: 497-509, 1957.

34. Rohwedder A, Zhang Q, Rudge SA and Wakelam MJ: Lipid droplet formation in response to oleic acid in Huh-7 cells is mediated by the fatty acid receptor FFAR4. J Cell Sci 127: 3104-3115, 2014

35. Gunn PJ, Green CJ, Pramfalk C and Hodson L: In vitro cellular models of human hepatic fatty acid metabolism: Differences between Huh7 and HepG2 cell lines in human and fetal bovine culturing serum. Physiol Rep 5: e13532, 2017.

36. Mota de SáP,Richard AJ,Hang H and Stephens JM: Transcriptional regulation of adipogenesis. Compr Physiol 7: 635-674, 2017.

37. Strable MS and Ntambi JM: Genetic control of de novo lipogenesis: Role in diet-induced obesity. Crit Rev Biochem Mol Biol 45: 199-214, 2010.

38. Adwan G and Mhanna M: Synergistic effects of plant extracts and antibiotics on Staphylococcus aureus strains isolated from clinical specimens. Middle East J Sci Res 3: 134-139, 2008.

39. Akila M and Devaraj H: Synergistic effect of tincture of Crataegus and Mangifera indica L. extract on hyperlipidemic and antioxidant status in atherogenic rats. Vascul Pharmacol 49: 173-177, 2008

40. Rosen ED, Hsu CH, Wang X, Sakai S, Freeman MW, Gonzalez FJ and Spiegelman BM: C/EBPalpha induces adipogenesis through PPARgamma: A unified pathway. Genes Dev 16: 22-26, 2002.
41. Abe M, Ozawa Y, Morimitsu Y and Kubota K: Mioganal, a novel pungent principle in myoga (Zingiber mioga Roscoe) and a quantitative evaluation of its pungency. Biosci Biotechnol Biochem 72: 2681-2686, 2008

42. Abe M, Ozawa Y, Uda Y, Yamada Y, Morimitsu Y, Nakamura Y and Osawa T: Labdane-type diterpene dialdehyde, pungent principle of myoga, Zingiber mioga Roscoe. Biosci Biotechnol Biochem 66: 2698-2700, 2002.

43. Iwasaki Y, Tanabe M, Kayama Y, Abe M, Kashio M, Koizumi K, Okumura Y, Morimitsu Y, Tominaga M, Ozawa Y, et al: Miogadial and miogatrial with alpha,beta-unsaturated 1,4-dialdehyde moieties - novel and potent TRPA1 agonists. Life Sci 85: 60-69, 2009.

44. Wani T, Wani S, Ahmad M, Ahmad M, Gani A and Masoodi FA: Bioactive profile, health benefits and safety evaluation of sea buckthorn (Hippophae rhamnoides L.): A review. Cogent Food Agric 2: 1-19, 2016.

45. Lee YJ, Choi HS, Seo MJ, Jeon HJ, Kim KJ and Lee BY: Kaempferol suppresses lipid accumulation by inhibiting early adipogenesis in 3T3-L1 cells and zebrafish. Food Funct 6: 2824-2833, 2015.

46. Lee J, Jung E, Lee J, Kim S, Huh S, Kim Y, Kim Y, Byun SY, Kim YS and Park D: Isorhamnetin represses adipogenesis in 3T3-L1 cells. Obesity (Silver Spring) 17: 226-232, 2009.

47. Ma Q, Cui Y, Xu S, Zhao Y, Yuan H and Piao G: Synergistic inhibitory effects of acacetin and 11 other flavonoids isolated from Artemisia sacrorum on lipid accumulation in 3T3-L1 cells. J Agric Food Chem 66: 12931-12940, 2018.

48. Sati P, Dhyani P, Bhatt ID and Pandey A: Ginkgo biloba flavonoid glycosides in antimicrobial perspective with reference to extraction method. J Tradit Complement Med 9: 15-23, 2018.

49. Salans LB, Cushman SW and Weismann RE: Studies of human adipose tissue. Adipose cell size and number in nonobese and obese patients. J Clin Invest 52: 929-941, 1973.

50. Wang Z, Kim JH, Jang YS, Kim CH, Lee JY and Lim SS: Anti-obesity effect of Solidago virgaurea var. gigantea extract through regulation of adipogenesis and lipogenesis pathways in high-fat diet-induced obese mice (C57BL/6N). Food Nutr Res 61: 1273479, 2017.

51. Shao X, Wang M, Wei X, Deng S, Fu N, Peng Q, Jiang Y, Ye L, $\mathrm{Xie} \mathrm{J}$ and Lin Y: Peroxisome proliferator-activated receptor- $\gamma$ : master regulator of adipogenesis and obesity. Curr Stem Cell Res Ther 11: 282-289, 2016.

52. Wang Y, Viscarra J, Kim SJ and Sul HS: Transcriptional regulation of hepatic lipogenesis. Nat Rev Mol Cell Biol 16: 678-689, 2015.

53. Aragno M, Tomasinelli CE, Vercellinatto I, Catalano MG, Collino M, Fantozzi R, Danni O and Boccuzzi G: SREBP-1c in nonalcoholic fatty liver disease induced by Western-type high-fat diet plus fructose in rats. Free Radic Biol Med 47: 1067-1074, 2009.

54. Longato L, Tong M, Wands JR and de la Monte SM: High fat diet induced hepatic steatosis and insulin resistance: Role of dysregulated ceramide metabolism. Hepatol Res 42: 412-427, 2012.

55. Vallim T and Salter AM: Regulation of hepatic gene expression by saturated fatty acids. Prostaglandins Leukot Essent Fatty Acids 82: 211-218, 2010 